\title{
The Disposition of Failed Bank Assets: Put Guarantees or Loss-Sharing Arrangements?*
}

\author{
Mark M. Spiegel ${ }^{\dagger}$
}

September 24, 2001

\begin{abstract}
A bstract
To mitigate the regulatory losses associated with bank failures, efforts are usually made to dispose of failed bank assets quickly. However, this process usually precludes due diligence examination by acquiring banks, leading to problems of asymmetric information concerning asset quality. This paper examines two mechanisms that have been used for dealing with these problems, "put guarantees," under which acquiring banks are allowed to return assets to the regulatory authority for liquidation, and "loss-sharing arrangements," under which the acquiring banks keep all assets under their control to maturity and are then compensated by the regulatory authority for a portion of asset losses. The analysis is conducted in a Hart-Moore framework in which the removal of certain assets from the banking system can reduce their value. Changes in the relative desirability of the two guarantee mechanisms during economic downturns are shown to depend on the credibility of the regulatory authority. When the regulatory authority enjoys credibility, a downturn favors the loss-sharing arrangement, while when the regulatory authority lacks credibility, the impact of a downturn is ambiguous.
\end{abstract}

\section{J.E.L. Classification Number: G21, G38}

Keywords: banks, failures, asset disposition

*Send correspondence to Mark M. Spiegel, Economic Research, Federal Reserve Bank of San Francisco, 101 Market St., San Francisco, CA, 94105, mark.spiegel@sf.frb.org, (415)-974-3241.

†Opinions in this paper are the author's own, and do not necessarily reflect those of the Federal Reserve Bank of San Francisco or the Board of Governors of the Federal Reserve. 


\section{Introduction}

Bank failures are a common feature of distressed financial systems. When bank failures occur, losses to the regulatory authority are likely to be substantial. For example, James (1991) finds that losses in a sample of US bank failures averaged 30 percent of bank assets.

These failures can be even greater when they occur at a more rapid pace than these agencies are designed to handle. For example, during the financial difficulties faced in the United States in the 1980s, the FDIC and the FSLIC found themselves acquiring bank assets at an astonishing pace. Between 1988 and 1992, one bank or savings and loan failed on average every day, bringing an average of $\$ 385$ million in assets to the regulatory authorities for disposition [FDIC (1998)].

Prior to this period, the FDIC had only sold the liabilities of a failed bank, along with "clean assets," such as cash and cash equivalents, to a healthy acquiring bank in a standard purchase and assumption (P\&A) transaction. ${ }^{1}$ However, in an effort to avoid the undesirable buildup of assets described above, the institution began selling a wider variety of assets in its P\&A transactions, including outstanding loans [FDIC (1998)].

Moreover, because of the desire to maintain secrecy concerning impending bank failures, P\&A transactions were customarily done without allowance for due diligence procedures. ${ }^{2}$ In response, when it widened the set of assets included in $\mathrm{P} \& \mathrm{~A}$ transactions, the FDIC began providing the acquiring bank with a put guarantee on its purchased assets. This put guarantee typically allowed the

\footnotetext{
${ }^{1}$ Cash equivalents include the failed bank's securities portfolio and other assets for which a market price was widely quoted. Transactions in these assets would then take place at the market price.

${ }^{2}$ Standard practice under due diligence would have given the acquiring bank assets to more information concerning the quality of the failied bank's outstanding loans, as well as more time to process this information.
} 
acquiring bank to return substandard assets to the FDIC at full face value during the first year following acquisition, and at a discount to face value for the next two years [Rosengren and Simons (1992)]. This type of P\&A transaction was used widely used in the United States for the bulk of resolutions from the mid1980's until 1991, and was recently the type of transaction featured in the sale of the failed Long-Term Credit Bank (LTCB) and Nippon Credit Bank (NCB) in Japan. $^{3}$

The preponderance of empirical evidence suggests that the bids in P\&A transactions are low, in the sense that winning bidders in FDIC and FSLIC auctions experience positive abnormal returns [James and Wier (1987), Balbirer, et al (1992), Gupta, et al (1993)]. However, Gupta, et al (1997) and Stover (1997) find that winning bidders in RTC auctions did not experience statistically significant abnormal returns.

The FDIC quickly noted some difficulties with the put guarantee transaction. First, acquiring banks responded to the guarantees by what was referred to as "cherry-picking," by retaining only assets with market values that exceeded their book values and returning the rest to the FDIC. Second, it appeared that the acquiring banks were failing to put the usual level of effort into the monitoring and administration of loans covered by the put guarantees [FDIC (1998)].

In response, the FDIC implemented loss sharing arrangements in selected P\&A transactions. Under these arrangements, the FDIC agrees to absorb a portion of the loss, typically 80 percent, and the acquiring bank is responsible for the remaining portion of the loss. These arrangements were implemented in 16 agreements involving 24 failed banks between 1991 and 1993. As loss sharing arrangements were typically involved in the failures of larger banks, these agreements involved

\footnotetext{
${ }^{3}$ After 1991, the FDIC found it more effective to separate assets into pools of common characteristics and sell the pools separately from the deposit operations of the failed institution [FDIC (1998)].
} 
40 percent of the total failed bank assets resolved over this period [FDIC (1998)].

Loss sharing arrangements appear to enjoy a number of advantages over standard P\&A transactions with put guarantees: First, redeeming the guarantee under the loss sharing arrangement does not require liquidation of the underlying asset. Assets that have higher value within the banking system will remain under the control of the bank to maturity. Second, under the loss sharing arrangement, the acquiring bank earns a share of the ultimate payoff from the borrower. Consequently, his incentives are in line with those of the regulatory authority, so he acts to maximize the expected value of the payoff of the loan.

Applications of loss-sharing arrangements have been primarily limited to larger bank failures. The primary reason offered by the FDIC appears to be that they are costly to implement. In addition, a loss-sharing arrangement may force the acquiring bank to retain assets for which it lacks management expertise. This could limit the number of potential acquiring banks and reduce the proceeds from the sale of the failed bank [FDIC (1998)].

Rosengren and Simons $(1992,1994)$ suggest the adoption of "transferable puts," as a way to mitigate the flaws in standard P\&A transactions. Under transferable puts, the government guarantee associated with a problem loan would be transferable to any bank that acquires the asset. Rosengren and Simons argue that transferable puts would carry a number of advantages over the standard put guarantee described above. First, the transferable put would eliminate the 90-day deadline for full refund that existed on FDIC transactions, allowing whoever held the asset to put it back to the regulatory authority for three years after the acquisition date. This would eliminate the incentive to immediately dispose of assets of uncertain value because the current exercise value of the option exceeds its future value. Second, assets with good prospects for success can remain in the banking system for the duration of the put guarantee. Therefore, the status of the asset would not be subject to either the financial constraints of the acquiring 
bank or its idiosyncratic beliefs concerning the asset's underlying value.

However, a transferable put mechanism still differs from the loss sharing arrangement in several fundamental manners: First, at the date at which it is exercised, the value of the transferable put to its owner is independent of the underlying value of the asset. As a result, the problems associated with put guarantees are reduced, but not eliminated. To the extent that agents believe that the put option will be exercised, the incentives of the bank holding the asset to work with a problem debtor are reduced. This is not the case with a loss sharing arrangement, where the acquiring bank retains an equity stake in the underlying asset that aligns his interests with those of the regulatory authority. Second, while a transferable put guarantee might have a longer maturity than a standard one, there must still be a fixed terminal date for its exercise. For example, Rosengren and Simons consider a transferable put guarantee with a maturity of three years. Otherwise, the risk of the underlying asset would be largely switched from the acquiring bank back to the regulatory authority. In contrast, loss sharing arrangements in practice lasted from four to six years after acquisition of the failed bank.

In this paper, I introduce a framework for evaluating the relative desirability of loss sharing arrangements and standard $\mathrm{P} \& \mathrm{~A}$ transactions. I introduce a simple model of bank borrowing that is an extension of Hart and Moore [HM (1998)]. In this model, the acquiring bank can profitably renegotiate with a problem debtor, while the regulatory authority cannot. This implies that there are assets which are more valuable inside the banking system than they would be to a non-bank, such as the regulatory authority. This assumption implies that liquidating good assets prior to sale is likely to be costly. Evidence in favor of this is provided by James (1991), who argues that even after controlling for asset quality, the value of assets is higher in the banking system than under the receivership of the regulatory authority. This loss is also known in regulatory circles, and is commonly referred 
to as the "liquidation differential," [Carns and Nejezchleb (1992)]. This condition also implies that the exercise of a put guarantee in this environment is costly, because it takes these assets out of the banking sector and thereby reduces their value.

The model extends the HM (1998) model by assuming that only a subset of loans, referred to as "good" loans below, are better mediated within the banking system. The first-best treatment of the remaining "bad" loans is immediate liquidation by the regulatory authority. The regulatory authority is assumed to know the type of loans, but because of the desire to dispose of the failed bank assets quickly, the acquiring bank does not. This sets up a situation of asymmetric information, where the regulatory authority first designates assets as good or bad. Good assets are to be included in the sale to the acquiring bank, while bad assets are immediately liquidated.

The regulatory authority faces an exogenous penalty for false designation of assets. This penalty may be related to its future credibility or other considerations, but I do not formalize them here. This leads to two possible equilibria: One where the regulatory authority enjoys credibility in the designation of assets and one in which it lacks credibility.

In this environment, I consider the implications of the regulatory authority offering both put guarantees and loss-sharing arrangements of fixed magnitudes. To keep the analysis simple, I assume that bidding is competitive with a representative acquiring bank purchasing the assets of the failed bank at its reservation price. $^{4}$

The results demonstrate that the payoff from introducing either put guaran-

\footnotetext{
${ }^{4}$ Some studies would suggest that bidding is not perfectly competitive [e.g. Ely and Varaiya (1997), Gardner and Stover (1997)], as the process used in the sale of assets, such as the Accelerated Resolution Policy pursued by the RTC, affect the losses to the regulatory authority in failed bank dispositions.
} 
tees or loss-sharing arrangements are dependent on their impact on the credibility of the regulatory authority. Introducing a put guarantee or a loss-sharing arrangement that fails to alter the credibility status of the regulatory authority unambiguously lowers the expected revenue from the sale of the assets of the failed bank. However, if the introduction of the guarantee moves the regulatory authority from a position of lacking credibility to enjoying credibility, it is possible that it could raise the expected net proceeds to the regulatory authority of the failed bank.

I also derive the level of administrative costs under the loss-sharing arrangement that, given the administrative costs of a put guarantee, would leave the regulatory burden under both types of guarantees equal. I then conduct a comparative static exercises concerning the impact of economic downturns on the relative desirability of the two guarantees. Two arguments that are parametric to the model are likely to decline as a result of an economic downturn. The first is the liquidation value of the asset while the second is the share of assets that are suitable for intermediation. Formally, these are also the assets in the model whose expected value declines under liquidation. The results show that the changes in the administrative costs that would leave the loss-sharing arrangement equivalent in expected regulatory payoff to the put guarantee are dependent on the credibility of the regulatory authority in its designation of assets. When the regulatory authority enjoys credibility, economic downturns unambiguously favor the losssharing arrangement. However, when the regulatory authority lacks credibility, the relative impact of an economic downturn on the relative desirability of the two guarantee mechanisms is ambiguous.

The remainder of this paper is divided into seven sections. Section two sets up the basic model. Section evaluates the expected proceeds to the regulatory authority when it offers not guarantees. Section four evaluates the expected proceeds to the regulatory authority under the put guarantees, while section five 
evaluates the expected proceeds to the regulatory authority under the loss-sharing arrangement. Section six compares the proceeds under the guarantee mechanisms, and conducts the comparative static analysis discussed above. Section seven concludes.

\section{Setup}

There are three players in the model, the regulatory authority who is selling the assets of the failed bank, the acquiring bank, and the borrower. All agents are assumed to be risk neutral and discount at the market rate, which is set to 0 for simplicity, and be interested only in maximizing period 3 wealth. ${ }^{5}$

There are four periods, $0,1,2$, and 3 . In period 0 , there is a failed bank under the control of the regulatory authority with a continuum of assets. The failed bank is assumed to be small relative to the size of the overall banking sector. The bank's assets are all debt contracts. The acquiring bank is assumed to face a fixed cost $b$ of administrating an asset. The borrowers underlying these assets are assumed to have cash positions, $C$, that are unobservable to the acquiring bank. These cash positions are assumed to be protected from seizure by creditors. However, as in the Hart-Moore (1998) model, they can influence loan payoffs under renegotiation. $C$ is assumed to be normally distributed with distribution $f(\cdot)$ and density $F(\cdot)$.

Borrowers are allowed to be of two types: A share $1-\pi(0<\pi<1)$ of the assets in the population are "good" loans, while the remaining $\pi$ share of the assets are "bad" loans. Borrowers of a certain class of loan, good or bad, are identical ex-ante, and the analysis is conducted in terms of a representative good and bad loan. For simplicity, I normalize the asset size of the bank so that it is

\footnotetext{
${ }^{5}$ Benveniste, et al (1994) consider the implications of risk aversion in the maintenance of distressed assets.
} 
expected to have $(1-\pi)$ good loans and $\pi$ bad loans.

Good loans and bad loans are assumed to differ in their investment opportunities. In particular, good loans are assumed to behave similarly to the Hart and Moore (1998) model. Loans have divisible underlying assets that last two periods, and are worthless in period 3. These asset yields uncertain return $R_{2}$ in period 2 and $R_{3}$ or 0 in period 3, depending on the loan's type. $R_{2}$ is also assumed to be normally distributed, with distribution $h(\cdot)$ and density $H(\cdot)$. These funds are also assumed to be under the control of the borrower, and not subject to seizure by the bank. Investments in place for good loans yield return $R_{3}$ in period 3, while investments in place for bad loans yield return 0 in period 3. In addition, any funds retained by good loan borrowers at the end of period 2 can be reinvested in the project at rate of return $s$, where

$$
1 \leq s \leq \frac{R_{3}}{L}
$$

where $L$ represents the liquidation value of the asset, which is assumed to be a constant. ${ }^{6}$

This implies that the return on reinvested capital for good loans is between the market rate of interest (which is zero) and the initial third period return on the project. To keep the analysis simple, I assume that $s$ is constant and that the above condition holds with absolute inequality. This assumption implies that the going-concern value of the project exceeds its liquidation value, so that liquidation is costly. The assumption also implies that the borrower would never liquidate his project to service debt if cash was available.

In contrast, borrowers of bad loans are assumed to face a return on reinvestment which is below the market rate. This implies that liquidation is a first-best

\footnotetext{
${ }^{6}$ If $\mathbf{L}$ was allowed to be uncertain, Hart and Moore show that the assumption that its realization is nonverifiable would be necessary to prove that a debt contract is optimal. Since loss-sharing agreements require that losses are verifiable, that assumption cannot be used here. Therefore, I take $\mathbf{L}$ as constant.
} 
outcome for bad borrowers.

In the spirit of a rapid asset sale, the acquiring bank is not allowed to conduct due diligence examination of the failed bank's assets prior to acquisition. As a result, the acquiring bank is assumed to lack knowledge about the share of good and bad loans in the failed bank's asset portfolio. Instead, the regulatory authority designates loans as good or bad. Loans designated as good are to be included in the asset sale of the failed bank, while loans designated as bad are immediately liquidated. Note that because of the administrative cost of carrying loans in the banking system, the immediate liquidation of bad loans is the firstbest outcome. Competitive bidding is assumed to insure that assets designated as suitable are sold to the acquiring bank at its reservation price. ${ }^{7}$

For there to be any possibility that the regulator properly designates the assets as suitable or unsuitable, it must find it costly to be found to be overstating the suitability of assets ex post. I model this as the regulatory authority suffering an exogenous penalty, $P$, when it is found to be untruthful. ${ }^{8}$

The timing of the model is as follows: In period 0 , the regulatory authority designates the types of the failed bank's assets. Those assets classified as good are sold to the acquiring bank for the agreed-upon price. In period 1, the acquiring firm learns each asset's true type as well as the cash position of its underlying borrower. The sold bank assets may carry either a put guarantee or a losssharing arrangement, as discussed below. If the asset carries a put guarantee,

\footnotetext{
${ }^{7}$ This assumption may not be representative for FDIC failed bank auctions. James and Wier (1987) find a significant relationship between the number of bidders in a failed bank auction and the abnormal returns to the winning bidder after the auction, suggesting that in practice competition among acquiring banks is less than perfect.

${ }^{8}$ The form of the penalty function is non-trivial. The fixed penalty assumed here implies that any deviation from accurate asset designation will result in the corner solution of all assets being designated as appropriate. I do not consider a penalty which is increasing in the number of incorrectly-designated assets. Such a function may induce an interior solution.
} 
the acquiring bank can exercise it in period 1. If the asset carries a loss-sharing arrangement, the acquiring bank is assumed to be partially compensated for his asset losses in period 3 .

The remaining underlying framework follows the Hart-Moore model. The assets call for a fixed contractual payment from the borrower to the debtor equal to $\bar{D}$ in period 2. If the borrower defaults on the asset, the acquiring bank has the option of liquidating it. In practice, bad loans will be liquidated. However, for good loans, seizure plays the role of a threat point, serving as a starting point for renegotiation between good borrowers and the acquiring bank.

Let $n$ represent the share of assets which are not liquidated, where $n \epsilon[0,1]$. Receipts from liquidation at date 1 are then equal to $(1-n) L$ and the borrower's earnings from the project at date 3 will equal $n R_{3}$, the realized return on the non-liquidated assets.

At period 2, the borrower has assets equal to $C+R_{2}$ which are not exposed to seizure. It follows that the borrower is solvent if and only if

$$
C+R_{2}+L \geq \bar{D}
$$

If the borrower is solvent, he can either make the payment $\bar{D}$ or choose to default. If the borrower is insolvent, he defaults with certainty. In the event of default and no renegotiation, the project is completely liquidated. In this case, the bank gets $L$, the liquidation value of the asset, while the borrower gets $C+R_{2}$.

Since the rate of return on even reinvested funds by the good borrower exceeds the market rate of interest, both sides can do better through renegotiation. As in HM, I assume that with probability $\alpha$ the bank would get to make a take-it-orleave-it offer to the borrower, while with probability $(1-\alpha)$ the borrower would get to make a take-it-or-leave-it offer to the bank. Moreover, I assume that the outcome of the renegotiation process is that the borrower makes an offer prior to the start of the game equal to the expected value of the payoffs to the creditor, which is always accepted. 
The details of the renegotiation process are shown in the appendix. The expected payoff from a good loan subsequent to the realization of $C$ is shown to be equal to $G(C)-b$, where $G(C)$ satisfies

$$
G(C)=\bar{D} \int_{R_{2}^{*}}^{\infty} h\left(R_{2}\right) d R_{2}+\int_{-\infty}^{R_{2}^{*}} D\left(C, R_{2}\right) h\left(R_{2}\right) d R_{2}
$$

where $R_{2}^{*}$ represents the realization of $R_{2}$ at which equation 2.2 is just binding and $D\left(C, R_{2}\right)$ represents the payment by the borrower after renegotiation. As shown in the appendix, $D\left(C, R_{2}\right)$ satisfies

$$
D\left(C, R_{2}\right)=(1-\alpha) L+\alpha\left[+\min \left\{-\left(\frac{C+R_{2}-R_{3}}{s}\right),\left(1-\left(\frac{C+R_{2}}{R_{3}}\right)\right) L\right\}\right]
$$

which represents the probability-weighted payoffs when the bank and the borrower are allowed to make take-it-or-leave-it offers respectively. I also demonstrate in the appendix that $G^{\prime}(C)>0$ and $G^{\prime \prime}(C)<0$.

In contrast to the good loan solution above, bad loans are completely liquidated subsequent to its period 2 return because the third-period return on both investment in place and reinvestment by bad borrowers falls short of the market rate. In this case, the borrower will always choose to default on its debt obligations subsequent to its realization of $R_{2}$ and then be liquidated. The return to the acquiring bank of a loan to a bad borrower then satisfies $L-b$.

\section{No guarantees}

To provide a benchmark to evaluate the proceeds of sales under the different guarantees considered in the paper, I first evaluate the proceeds that the sale of the failed bank would generate without any guarantees.

Given the fixed penalty $P$ for misleading the acquiring bank, there are two possible strategies for the regulatory authority: Properly classifying the assets 
(credibility) or identifying all of the assets as appropriate (lack of credibility). I confirm that two types of belief sets may emerge in equilibrium below. I examine each in turn.

First, let $\Pi_{c}$ represent the payoff to the regulatory authority under credibility with no loss-coverage guarantee. $\Pi_{c}$ is equal to the sum of its revenues from the sale of the failed bank and the proceeds from the liquidation of bad loans. Since the acquiring bank believes that the regulatory authority will offer only good loans for sale, it values these assets at $G-b$, where $b$ is the fixed cost of administering the loan. Since a $\pi$ share of assets are unsuitable, $\Pi_{c}$ satisfies

$$
\Pi_{c}=\pi L+(1-\pi)(G-b) .
$$

I show in the appendix that the credibility case with no guarantee will be a Nash equilibrium if and only if

$$
P \geq \pi[G-b-L]
$$

The above condition is intuitive, stating that the credibility case is a Nash equilibrium if the payoff from representing all assets as suitable is less than the penalty. If the penalty is this high, the regulatory authority will properly designate the assets and the acquiring bank will for the assets on the basis of the belief that the assets have been properly designated. On the right-hand side, the benchmark is equal to the share of bad loans, $\pi$, times the difference in proceeds from selling the bad loans and liquidating them.

Second, I turn to the lack of credibility case. Let $\Pi_{n}$ represent the payoff to the regulatory authority under no credibility when no guarantees are extended. Under lack of credibility, the regulatory authority misclassifies all of the assets as suitable, and the acquiring bank assumes that the share of unsuitable assets is equal to that in the population, or $\pi$. The acquiring bank is therefore only willing 
to bid $\pi(L-b)$ for these assets. $\Pi_{n}$ therefore satisfies

$$
\Pi_{n}=\pi L+(1-\pi) G-b-P
$$

I show in the appendix that lack of credibility case with no guarantee will be a Nash equilibrium if and only if

$$
P \leq \pi[(1-\pi)(G-L)-b] .
$$

Comparing conditions 3.2 and 3.4, the minimum value of $P$ consistent with the credibility case exceeds the maximum value of $P$ consistent with the lack of credibility. This implies that there is a range of values for $P$ under where if the regulatory authority enjoyed credibility, he would optimally respond by designating all of the assets as unsuitable. Instead, if the regulatory authority lacked credibility, he would properly designate the assets. Intuitively, this discrepancy stems from the fact that lacking credibility reduces the gains from misclassifying assets. It is clear that this space fails to yield a Nash equilibrium, so I concentrate on values of $P$ for which one of the two conditions above is satisfied.

Subtracting $\Pi_{n}$ from $\Pi_{c}$ yields

$$
\Pi_{c}-\Pi_{n}=\pi b+P
$$

Equation 3.5 calculates the loss in regulatory authority revenues associated with the lack of credibility. This loss is equal to the administrative costs incurred on the bad assets, plus the penalty. The administrative loss on bad assets reflects the losses incurred from assets remaining in the banking system that would be better liquidated immediately.

\section{Put Guarantee}

In this section, I consider the provision of a put guarantee analogous to that which prevailed in the LTCB, NCB and pre-1991 United States failed bank auc- 
tions. These guarantees emerged as a response to the credibility problem discussed above. They allow the acquirer to return either bad assets or good assets with sufficiently low valuations to the regulatory authority for liquidation.

This can be motivated in the context of the above model. Recall that in period 1 the acquiring bank learns each borrower's cash position, $C$. A low realization of $C$ has adverse implications for expected loan payoffs. This raises the possibility that the acquiring bank may wish to return a good loan with a sufficiently low realization of $C$. However, the return of the loan to the regulatory authority would result in a deadweight loss because as a good loan, it would by definition be more valuable within the banking sector than it would be under liquidation.

To make the problem non-trivial, I assume that the put guarantee is sufficiently valuable that the acquiring bank would prefer to exercise it under some states of the world. Since the minimum level of cash holdings, $C$, is 0 , the required assumption is that the put guarantee $\Lambda$ is sufficiently large that the acquiring bank would choose to return the asset upon discovering that the borrower's cash position was 0 if she could, but not as large as $\bar{D}$, the asset's contractual rate of return.

It is straightforward that the acquiring bank will choose to return a loan when its expected payoff falls short of the put guarantee, i.e. when

$$
\Lambda \geq G(C) .9
$$

The assumption that the put guarantee is sufficiently large that it would be exercised in some, but not all, states for good borrowers is then

$$
\bar{D}>\Lambda>G(0)
$$

which I adopt.

Define $C^{*}(\Lambda)$ as the borrower cash position under the put guarantee for which assets are returned if $C<C^{*}$ and assets are retained if $C \geq C^{*}$. It is easy to 
demonstrate that $C^{*}(\Lambda)$ exists and is unique: Since cash holdings cannot be negative, existence follows directly from assumption 4.2 and the result in the appendix that $G(C)$ is strictly increasing in $C$. Suppose that $C=0$. By assumption 4.2, the acquiring bank would choose to return the asset to the regulatory authority at $C=0$. Now consider the payoffs as $C$ approaches infinity. By equation ??, as $C \rightarrow \infty$ the probability of default goes to zero. It follows that $G(C) \rightarrow D$ as $C \rightarrow \infty$. Since $D>\Lambda$ by assumption, it follows that the acquiring bank would not return the asset if $C$ approached infinity. It follows that a unique value of $C^{*}$ exists. Moreover, $C^{*}$ is the value of $C$ under which the constraint in equation 4.1 is just binding.

Let $V^{p}$ represent the acquiring bank's valuation of a good asset under the put guarantee. $V^{p}$ satisfies

$$
V^{p}=\Lambda F\left(C^{*}\right)+\int_{C^{*}}^{\infty} G(C) f(C) d C-b
$$

where $C^{*}$ is the value of $C$ for which condition 4.1 is just binding.

As above, I analyze the credibility and lack of credibility cases to determine the ranges which result in Nash equilibria in the presence of the put guarantee. I first consider the credibility case. Let $\Pi_{c}^{p}$ represent the payoff to the regulatory authority under complete credibility with a put guarantee of magnitude $\Lambda$ is offered and all assets are properly classified. $\quad \Pi_{c}^{p}$ is equal to the sum of its revenues from the sale of the failed bank and the proceeds from the liquidation of unsuitable assets, since no unsuitable assets are offered or returned. $\Pi_{c}^{p}$ therefore satisfies

$$
\Pi_{c}^{p}=\pi L+(1-\pi)\left[V^{p}-(\Lambda-L) F\left(C^{*}\right)\right] .
$$

where

$$
(\Lambda-L) F\left(C^{*}\right)
$$


represents the expected cost of servicing the put guarantee.

I demonstrate in the appendix that the Nash condition for the regulatory authority to have credibility is

$$
P \geq \pi\left(V^{p}-\Lambda\right)
$$

Condition 4.5 states that the credibility case under the put guarantee is again a Nash equilibrium if the probability-weighted payoff from miss-classifying bad assets is less than the penalty. It is interesting to compare conditions 4.5 and 3.2. Let $P_{c}^{*}$ represent the value of the penalty for which condition 3.2 is just binding, while $P_{c}^{p *}$ represent the value of the penalty for which condition 4.5 is just binding. It follows from these conditions that

$$
P_{c}^{p *}-P_{c}^{*}=-\pi\left([\Lambda-L]\left[1-F\left(C^{*}\right)\right]+\int_{0}^{C^{*}}(G(C)-L) f(C) d C\right) .
$$

Since $\Lambda \geq L$, the second term in the above expression is of ambiguous sign because the acquiring bank returns assets when $G(C) \leq \Lambda$.However, under common distributions of $C$ the entire second term is likely to be negative. In any event, a sufficiently large value of $\Lambda$ removes the ambiguity entirely. The necessary and sufficient condition for $P_{c}^{p *}-P_{c}^{*}<0$ is

$$
\Lambda \geq \frac{1}{1-F\left(C^{*}\right)}\left[\int_{0}^{C^{*}} G(C) f(C) d C-L\right] .
$$

A sufficiently large put guarantee therefore reduces the penalty necessary for achieving credibility. Intuitively, the put guarantee can be understood as a mechanism for increasing the penalty faced by the regulatory authority for misclassifying assets.

Next, I turn to the case where a put guarantee is offered but the regulatory authority lacks credibility. As above, when the regulatory authority lacks credibility, the acquiring bank places the population probability $\pi$ that all assets designated as suitable are in fact unsuitable. Let $\Pi_{n}^{p}$ represent the payoff to the regulatory 
authority under no credibility when a put guarantee of magnitude $\Lambda$ is offered. Under lack of credibility, the regulatory authority misclassifies all of the assets as suitable, and the acquiring bank assumes that the share of unsuitable assets is equal to that in the population, or $\pi$. $\Pi_{n}^{p}$ satisfies

$$
\Pi_{n}^{p}=\pi(\Lambda-b)+(1-\pi) V^{p}-(\Lambda-L)\left[\pi+(1-\pi) F\left(C^{*}\right)\right]-P
$$

where the first two terms represent the probability-weighted values of the acquiring bank of bad and good assets respectively, the third term represents the expected cost of the put guarantee, and the fourth term is the penalty for misclassifying assets.

I demonstrate in the appendix that the Nash condition for the regulatory authority to lack credibility is

$$
P \leq \pi\left[(1-\pi)\left(V^{p}-\Lambda\right)-\pi b\right]
$$

As above, we can compare the penalties necessary for sustaining the no credibility Nash equilibrium in the presence and absence of the put guarantee. Let $P_{n}^{*}$ represent the value of the penalty for which condition 3.4 is just binding, while $P_{n}^{p *}$ represent the value of the penalty for which condition 4.9 is just binding. It follows from these conditions that

$$
P_{n}^{p *}-P_{n}^{*}=-\pi(1-\pi)\left[(\Lambda-L)\left[1-F\left(C^{*}\right)\right]+\int_{0}^{C^{*}}[G(C)-L] f(C) d C\right]
$$

Since the term that is ambiguous in sign in equation 4.10 is the same as that in equation 4.6, equation 4.7 is also the condition for $P_{n}^{p *}-P_{n}^{*} \leq 0$. Satisfaction of this condition implies that the put guarantee also reduces the penalty below which the lack of credibility is a Nash equilibrium. Again, this result can be understood as the put guarantee acting to enhance the severity of the penalty for designating unsuitable assets as suitable. 
I next turn to the question of the implications of the put guarantee on the expected net proceeds to the regulatory authority from the sale of the failed bank. First, suppose that $P$ is large enough to satisfy condition 3.2 and that condition 4.7 is satisfied. In this case, the regulatory regime will enjoy credibility with or without the introduction of the put guarantee. By equations 3.1 and 4.4, the return from offering a put guarantee when starting from the credibility case satisfies

$$
\Pi_{c}^{p}-\Pi_{c}=-(1-\pi)\left[\int_{0}^{C^{*}} G(C) f(C) d C-L F\left(C^{*}\right)\right]<0
$$

since $G(C) \geq L$ for all realizations of $C$ because the acquiring bank can profit from renegotiation on good loans.

The above expression demonstrates that when the regulatory authority enjoys credibility, offering a put guarantee lowers the returns to the regulatory authority. Due to competitive bidding and risk neutrality, the bid price exactly compensates the regulatory authority for expected payouts on the put guarantee. The difference is equal to the probability-weighted deadweight loss from the acquiring bank returning assets that would be better intermediated within the banking sector.

Second, I consider the case where the regulatory begins from a condition of lacking credibility, i.e. where condition 3.4 is satisfied. There are two possibilities: The regulatory authority could offer a small put guarantee, one which satisfies condition 4.9, which would leave it lacking credibility after the extension of the guarantee. Alternatively, it could offer a sufficient put guarantee to satisfy condition 4.5, which would bring it to the credibility Nash equilibrium. I therefore analyze both cases: That where the introduction of the unenforceable put option guarantee leaves the regulatory authority lacking credibility, and that where the introduction of the guarantee leaves the regulatory authority with credibility.

By equations 3.3 and 4.8 the gains to a regulatory authority that lacks credibility from introducing a put option guarantee that fails to lead to credibility 
satisfies

$$
\Pi_{n}^{p}-\Pi_{n}=-(1-\pi)\left[\int_{0}^{C^{*}} G(C) f(C) d C-L F\left(C^{*}\right)\right]<0 .
$$

The expected loss from introducing a put guarantee that fails to lead to credibility is again equal to the expected deadweight losses from the liquidation of suitable assets from the banking sector due to the acquiring bank exercising the put guarantee, rather than pursuing renegotiation.

In contrast, suppose that the regulatory authority extends a put option guarantee of sufficient magnitude to satisfy condition 4.5, i.e. to move from the lack of credibility case to the credibility case. By equations 3.3 and 4.5 the gains to a regulatory authority that lacks credibility from introducing an unenforceable put option guarantee which leads it to credibility satisfies

$$
\Pi_{c}^{p}-\Pi_{n}=\pi b+P-(1-\pi)\left[\int_{0}^{C^{*}} G(C)-L F\left(C^{*}\right)\right]
$$

which is ambiguous in sign. It can be seen that there are three components to the net gains from introducing an unenforceable put option guarantee. First there is the gain $\pi b$, corresponding to the regulatory authority not placing assets into the banking sector that are better liquidated immediately. Second, there is the gain $P$ from avoiding the penalty for misclassifying assets. Finally, there are the expected losses from the liquidation of assets from the banking sector due to the acquiring bank exercising the put option guarantee.

\section{Loss-sharing arrangement}

\subsection{Setup}

I next consider the extension of a loss-sharing arrangement. I assume that the purchaser of the asset is guaranteed a reimbursement of $\phi$ times the magnitude by 
which the loan payoff falls short of its face value $\bar{D}, \phi \epsilon(0,1)$. Let $b^{\prime}$ represent the acquiring banks administrative costs of maintaining the loss-sharing arrangement. In keeping with the literature, I assume that $b^{\prime} \geq b$, i.e. that the maintenance of the loss-sharing arrangement raises the acquiring bank's administrative costs.

Let $V_{u}^{l}$ represent the expected return to the acquiring bank of an unsuitable asset inclusive of the loss-sharing arrangement. Unlike the put guarantee case, under the loss-sharing case, the acquiring bank does not return assets to the regulatory authority. Assets that are found to unsuitable will be liquidated by the bank itself, and hence yield revenues of $L-b^{\prime}$ to the acquiring institution. $V_{u}^{l}$ satisfies

$$
V_{u}^{l}=L-b^{\prime}+\phi(\bar{D}-L)
$$

where $\phi(\bar{D}-L)$ is the payoff on unsuitable assets under the loss-sharing arrangement.

Let $V_{s}^{l}$ represent the expected return to the acquiring bank of a suitable asset inclusive of the loss-sharing arrangement. Moreover, let $\bar{R}_{2}(C)$ represent the realization of $R_{2}$ at which the borrower is indifferent between paying the debt service in full and default. $\bar{R}_{2}(C)$ satisfies

$$
D\left[C, \bar{R}_{2}(C)\right]=\bar{D}
$$

$V_{s}^{l}$ then satisfies

$$
V_{s}^{l}=G-b^{\prime}+\phi \int_{0}^{\infty} \int_{-\infty}^{\bar{R}_{2}(C)}\left[D-\bar{D}\left(C, R_{2}\right)\right] h\left(R_{2}\right) d R_{2} f(C) d C
$$

where $h(\cdot)$ represents the distribution of $C$ and the final term represents the expected payoff from the regulatory authority under the loss-sharing arrangement.

As above, I examine the payoffs of a loss-sharing arrangement under the credibility and lack of credibility cases. First, consider the credibility case. Let $\Pi_{c}^{l}$ represent the payoff to the regulatory authority under complete credibility under 
the loss-sharing arrangement. Under complete credibility, $\Pi_{c}^{l}$ is equal to the sum of its revenues from the sale of the suitable assets of the failed bank and the proceeds from the liquidation of unsuitable assets, minus the expected payoff under the loss-sharing arrangement. $\Pi_{c}^{l}$ therefore satisfies

$$
\Pi_{c}^{l}=\pi L+(1-\pi)\left(G-b^{\prime}\right)
$$

I demonstrate in the appendix that the Nash condition for the regulatory authority to have credibility under the loss-sharing arrangement is

$$
P \geq \pi\left(G-b^{\prime}\right)-\pi[\phi \bar{D}+(1-\phi) L]
$$

Note that the right-hand side argument in equation 5.5 is decreasing in $\phi$, the share of losses covered by the loss-sharing guarantee. An increase in the losssharing guarantee reduces the gains from misclassifying bad loans. As a result, the extension of the loss-sharing arrangement also may induce credibility.

Second, I turn to the lack of credibility case. Let $\Pi_{n}^{l}$ represent the payoff to the regulatory authority lacking credibility under a loss-sharing arrangement. Under lack of credibility, the acquiring bank assumes that the share of unsuitable assets is equal to that in the population, or $\pi$, and the regulatory authority missdesignates all assets as suitable for sale. $\Pi_{n}^{l}$ satisfies

$$
\Pi_{n}^{l}=\pi L+(1-\pi) G-b^{\prime}-P
$$

I demonstrate in the appendix that the Nash condition for the regulatory authority to lack credibility under the loss-sharing arrangement is

$$
\begin{aligned}
P & \leq \pi(1-\pi)(G-L)-\pi b^{\prime} \\
& -\phi \pi(1-\pi)\left[(\bar{D}-L)-\int_{0}^{\infty} \int_{-\infty}^{\bar{R}_{2}(C)}\left[\bar{D}-D\left(C, R_{2}\right)\right] h\left(R_{2}\right) d R_{2} f(C) d C\right]
\end{aligned}
$$


The latter term is positive, and as explained in the appendix, reflects the difference between the expected payoff under the loss-sharing arrangement and its true value when the regulatory authority deviates from the lack of credibility equilibrium. This term implies that the penalty necessary for the regulatory authority to lack credibility is decreasing in $\phi$. As above, this implies that the loss sharing arrangement acts as an increase in the penalty function and enhances credibility.

I next turn to the implications of the introduction of the loss-sharing arrangement for the expected revenues of the regulatory authority. By equations 3.1 and 5.4, the net gain from offering the loss-sharing arrangement when beginning from credibility satisfies

$$
\Pi_{c}^{l}-\Pi_{c}=-(1-\pi)\left(b^{\prime}-b\right) \leq 0 .
$$

Under competitive bidding, the regulatory authority is exactly compensated for the expected loss-sharing payout. The net difference from offering the loss-sharing guarantee is therefore the probability-weighted increase in administrative costs under the loss-sharing arrangement.

Next, I consider the impact of offering the loss-sharing arrangement which maintains the lack of credibility. By equations 3.3 and 4.8, the gains under no credibility from offering the loss-sharing arrangement, $\Pi_{n}^{l}-\Pi_{n}$, satisfy

$$
\Pi_{n}^{l}-\Pi_{n}=b-b^{\prime} \leq 0 .
$$

Again, the only change from offering a loss-sharing arrangement when the authority fails to achieve credibility is the increase in administrative costs to the acquiring bank. Note that the increase in administrative costs are greater under the lack of credibility case because the unsuitable assets are intermediated within the banking system as well.

Finally, I consider the impact of offering a loss-sharing arrangement of sufficient magnitude to induce credibility. By equations 5.4 and 3.3 , the gains from offering 
a loss-sharing arrangement which induces credibility, $\Pi_{c}^{l}-\Pi_{n}$, satisfy

$$
\Pi_{c}^{l}-\Pi_{n}=P+b-(1-\pi)\left(b^{\prime}\right)
$$

The term is of ambiguous sign, depending on the gain from avoiding the penalty, $P$, and the net change in administrative costs. The net change in administrative costs is itself of ambiguous sign because fewer assets are intermediated under the loss sharing agreement under credibility, but the cost per asset is larger. Obviously, if the increase in administrative costs per unit, $b^{\prime}-b$, is sufficiently small, the net impact on revenues is positive.

\section{Comparison of Put guarantee vs loss-sharing arrange- ment}

I next turn to comparing the payoffs from offering the loss-sharing arrangement to those obtained under the put guarantees. First, consider the case where both the loss-sharing arrangement and the put guarantee result in the regulatory authority enjoying credibility concerning asset designation. By equations 5.4, 4.3, and 4.4 the gain in revenues to the regulatory authority, $\Pi_{c}^{l}-\Pi_{c}^{p}$, satisfies

$$
\Pi_{c}^{l}-\Pi_{c}^{p}=(1-\pi)\left[\left(b-b^{\prime}\right)+\int_{0}^{C^{*}}(G(C)-L) f(C) d C\right] .
$$

Similarly, by equations 5.6, 4.3, and 4.8, the net gain from offering a losssharing arrangement relative to offering an enforceable put guarantee which maintains the lack of credibility, $\Pi_{n}^{l}-\Pi_{n}^{p}$, satisfies

$$
\Pi_{n}^{l}-\Pi_{n}^{p}=\left(b-b^{\prime}\right)+(1-\pi)\left[\int_{0}^{C^{*}}(G(C)-L) f(C) d C\right] .
$$

There are two components to the difference in revenues between the losssharing arrangement and the put guarantee under the presence or absence of 
credibility in both schemes. The first term is negative, reflecting the additional administrative costs under the loss-sharing arrangement. The second term is positive, reflecting that under the loss sharing arrangement suitable assets are never liquidated as they are under the put guarantee. The relative merits of the two policies is then dependent on the relative size of these two features.

Note that the negative term is greater under the lack of credibility than under the presence of credibility because all loans are classified as suitable. Holding all else equal, the relative superiority of the loss-sharing arrangement will be greater under credibility, as the additional administrative costs associated with the losssharing arrangement will be smaller.

I next turn to the comparison of offering the put guarantee and the losssharing arrangement where the credibility status of the regulatory authority differs depending on the guarantee offered. First, consider the case where the put guarantee fails to induce credibility while the loss-sharing arrangement is sufficient to induce credibility.

$$
\Pi_{c}^{l}-\Pi_{n}^{p}=\left[b-(1-\pi) b^{\prime}\right]+P+(1-\pi)\left[\int_{0}^{C^{*}}(G(C)-L) f(C) d C\right]
$$

The first term in the above expression is of ambiguous sign. The first term, which represents the net change in administrative costs, is ambiguous in sign because more assets are intermediated under the put guarantee. The second term is positive, reflecting the penalty from incorrectly designating asset quality under the put guarantee. Finally, the last term is again positive reflecting the gains under the loss sharing arrangement from avoiding the liquidation of suitable assets.

Second, I compare a loss-sharing arrangement under no credibility to a put guarantee that induces credibility. By equations 4.4, 4.3, and 5.6, the gains from offering a loss-sharing arrangement which fails to induce credibility relative to a 
put guarantee which yields credibility, $\Pi_{n}^{l}-\Pi_{c}^{p}$, satisfy

$$
\Pi_{n}^{l}-\Pi_{c}^{p}=\left[(1-\pi) b-b^{\prime}\right]-P+(1-\pi)\left[\int_{0}^{C^{*}}(G(C)-L) f(C) d C\right]
$$

The first term above again represents the difference in administrative costs. This time, however, it is unambiguously negative as more assets are intermediated under the loss-sharing arrangement and the cost per asset is also higher. The second term is also negative, as the regulatory authority suffers the penalty for designating assets incorrectly. However, the third term is positive, reflecting the gains from avoiding the liquidation of unsuitable assets under the loss-sharing arrangement, even though the regulatory authority lacks credibility.

In comparing the two forms of regulatory guarantees, it can be seen that in all cases an increase in the administrative cost differential reduces the relative desirability of the loss-sharing arrangement while an increase in the losses from the liquidation of suitable assets increases the relative desirability of the loss-sharing arrangement.

Define $b_{c}^{*}$ as the administrative cost of the loss-sharing program under credibility that leaves regulatory revenue exactly equivalent to the put option guarantee under credibility. By equation $6.1, b_{c}^{* *}$ satisfies

$$
b_{c}^{*}=b+\int_{0}^{C^{*}}(G(C)-L) f(C) d C
$$

Differentiating with respect to $L$ yields

$$
\frac{d b_{c}^{*}}{d L}=\frac{d C^{*}}{d L}\left(G\left(C^{*}\right)-L\right) f\left(C^{*}\right)+\int_{0}^{C^{*}}\left(\frac{d G}{d L}-1\right) f(C) d C
$$

By equations $2.2,2.3$ and $2.4 d C^{*} / d L$ satisfies

$$
\frac{d C^{*}}{d L}=-\frac{(\bar{D}-D) h\left(R_{2}^{*}\right)+\int_{-\infty}^{R_{2}^{*}} \frac{\partial D}{\partial L} h\left(R_{2}\right) d R_{2}}{(\bar{D}-D) h\left(R_{2}^{*}\right)+\int_{-\infty}^{R_{2}^{*}} \frac{\partial D}{\partial C} h\left(R_{2}\right) d R_{2}}<0
$$


It follows that a sufficient, but not necessary condition for $d b_{c}^{\prime *} / d L<0$ is then

$$
(\bar{D}-D) f\left(R_{2}^{*}\right)+\int_{-\infty}^{R_{2}^{*}} \frac{\partial D}{\partial L} h\left(R_{2}\right) d R_{2}<1
$$

Since $\partial D / \partial L \leq 1$ by equation 2.4 , the above condition is relatively weak, suggesting only that the sensitivity of the value of the asset under intermediation to the liquidation value can't exceed one. Under this condition, an increase in the liquidation value of the asset increases the relative desirability of liquidation.

Given satisfaction of this condition, a decrease in $L$, the liquidation value of the asset raises $b_{c}^{*}$, the loss-sharing administrative cost that leaves the regulatory authority indifferent between the put guarantee and loss-sharing arrangements under credibility.

It is easily verified that the analysis with respect to changes in $L$ under the other credibility situations analyzed above are similar.

However, once the regulatory authority lacks credibility under either the put guarantee or the loss-sharing arrangement, the other parameter in the study, $\pi$, the probability in the population that a loan is suitable also affects the relative desirability of the two guarantees. For example, consider the case where credibility is lacking under both the put guarantee and the loss-sharing arrangement. Let $b_{n}^{\prime *}$ represent the administrative cost of the loss-sharing arrangement that leaves the regulatory authority indifferent between the put option guarantee and the loss-sharing arrangement under no credibility. By equation 6.2,

$$
\frac{d b_{n}^{*}}{d \pi}=-\int_{0}^{C^{*}}(G(C)-L) f(C) d C<0 .
$$

An increase in $\pi$ reduces $b_{n}^{* *}$ because it lowers the share of suitable assets. When there are less suitable assets in the economy, the losses from the put guarantee associated with the return of assets that are more valuable under intermediation are smaller. As such, an increase in $\pi$ reduces the administrative costs 
of the loss-sharing arrangement that leave the regulatory indifferent between the two asset guarantees.

Unlike the case for changes in $L$, the impact of a change in $\pi$ on the mixed credibility cases is not equivalent. Differentiating equation 6.3 with respect to $\pi$ yields

$$
\frac{\partial\left(\Pi_{c}^{l}-\Pi_{n}^{p}\right)}{\partial \pi}=b^{\prime}-\int_{0}^{C^{*}}(G(C)-L) f(C) d C
$$

which is of ambiguous sign. The difference is of course the additional savings in administrative costs under the loss-sharing arrangement with an increase in $\pi$.With an increase in $\pi$, more assets are improperly placed in the banking system under the put option guarantee. Differentiating equation 6.4 with respect to $\pi$ yields

$$
\frac{\partial\left(\Pi_{n}^{l}-\Pi_{c}^{p}\right)}{\partial \pi}=-b-\int_{0}^{C^{*}}(G(C)-L) f(C) d C<0 .
$$

\section{Conclusion}

This paper introduced a model of failed bank asset disposition. Because of the desire for a quick asset sale, an asymmetric information problem existed between the regulatory authority, who had the responsibility of choosing the set of loans suitable for retention in the banking system, and the representative acquiring bank. The regulatory authority used two mechanisms to deal with this problem: A put guarantee, under which the acquiring bank can return assets for fixed amount, and a loss-sharing arrangement where the acquiring bank is compensated for a portion of asset losses after holding the loan to maturity. The overall superiority of either form of guarantee was shown to depend on the relative magnitude of the losses associated with loans being inappropriately liquidated from banking sector under the put guarantee and the higher administrative costs experienced under the loss-sharing arrangement. 
The results of the previous section suggest that it is difficult to make a uniform statement about changes in the relative desirability of the put guarantee and losssharing arrangements under good and bad economic times. In terms of the above model, there are two developments that would be associated with poor economic times: a decrease in the liquidation value of assets, and a decrease in the share of assets that are more valuable within the banking sector. As shown in the above section, these two changes have opposite effects. A decrease in the liquidation value of assets raises the relative desirability of the loss-sharing arrangement, because the losses under liquidation of an asset that would be better managed through the banking system are likely to be more costly. However, a decrease in the share of assets that would do better under intermediation has the opposite effect, as there are now less assets for which the problems associated with early liquidation of assets are viable.

The model therefore points to a number of potential avenues for extension. First, the relative impact of an economic downturn on these two developments has not been modeled above, and it would clearly be desirable to work out how economic downturns affect the share of assets better intermediated through the banking system, as well as the losses experienced by those assets when they are liquidated early. Of course, the model did show that economic downturns favor the loss-sharing arrangement when the regulatory authority enjoys credibility in its designation of assets as suitable or unsuitable for intermediation. It is only when credibility is absent even after the provision of the put option guarantee or loss-sharing arrangement that the issue becomes ambiguous.

There are a number of other possible extensions that have not been discussed in the above model. The most obvious one is risk. The above analysis assumes risk neutrality on the parts of all agents. It is certainly possible that allowing for risk aversion by agents in the model, including the regulatory authority, may affect the conclusions. 
Second, the model assumes a competitive bidding framework by banks attempting to acquire the failed bank. While this assumption greatly simplifies the analysis, it seems likely that in practice there will be a limited number of potential acquiring banks for a failed bank of even medium size. As such, strategic issues in the provision of guarantees to potential purchasers become important. It is possible that provisions could usefully be tailored to allow the regulatory authority to discriminate across potential acquiring banks. The problem of a small number of bidders appears to have special implications for loss-sharing arrangements. The FDIC (1998) notes that some banks are inexperienced at handling problem credits. These banks may lose interest in bidding for failed banks under a loss sharing arrangement. When the number of bidders is sufficiently small that the loss of these banks would affect the bidding outcome, the analysis above may overstate the relative desirability of a loss sharing arrangement.

Finally, the administration of loss sharing is likely to exhibit scale economies. Historically, loss-sharing arrangements have been used primarily in the resolution of large bank failures. Consideration of scale economies in loss-sharing arrangements may help to explain why such arrangements have been most prevalent historically in the United States in the resolution of large bank failures. 


\section{A ppendix}

\subsection{R enegotiation}

As in HM (1998), I model renegotiation by assuming that assume that with probability $\alpha$ the bank would get to make a take-it-or-leave-it offer to the borrower, while with probability $(1-\alpha)$ the borrower would get to make a take-it-or-leave-it offer to the bank. Moreover, I assume that the borrower can make an offer prior to the start of the game equal to the expected value of the payoffs to the creditor.

If the borrower could make a take-it-or-leave-it offer, the payoff to the bank would be equal to its status quo value of $L$, the amount it could obtain by liquidating the entire firm.

However, if the bank could make the take-it-or-leave-it offer, it would demand payment sufficient to reduce the payoff to the borrower to its status quo value of $C+R_{2}$, the total value of its assets which are protected from seizure by the bank. There are two possibilities for the bank's payoff depending on the wealth of the borrower in period 2: First, suppose that the borrower is relatively wealthy. In particular, suppose that $C+R_{2} \geq R_{3}$. In this case, the bank will demand a cash payment from the borrower equal to

$$
C+R_{2}-\left(\frac{C+R_{2}-E\left(R_{3}\right)}{s}\right) .
$$

This leaves the borrower with cash equal to $C+R_{2}-R_{3} / s$. This cash, reinvested at rate $s$ yields the payoff

$$
C+R_{2}-R_{3} \text {. }
$$

Combined with the expected return on the investment in place, $R_{3}$, this will leave the borrower at his status quo in period 3 .

Alternatively, suppose that the borrower is poor, i.e. that $C+R_{2}<R_{3}$. In this case, some amount of liquidation will be required to reduce the borrower's period 
3 payoff to $C+R_{2}$. In particular, the bank will demand all of the borrower's cash, $C+R_{2}$, plus the proceeds of sale from a partial liquidation of the asset. The bank will demand that the borrower liquidate a share of the assets equal to $1-\left(C+R_{2}\right) / R_{3}$. This again leaves the borrower at the status quo, with assets in place equal to $\left(C+R_{2}\right) / R_{3}$, which will yield $C+R_{2}$ in period 3 . The payoff to the bank in this case satisfies

$$
C+R_{2}+\left(1-\left(\frac{C+R_{2}}{R_{3}}\right)\right) L
$$

The payoff when the bank gets to make the take-it-or-leave-it offer then satisfies

$$
C+R_{2}+\min \left\{-\left(\frac{C+R_{2}-R_{3}}{s}\right),\left(1-\left(\frac{C+R_{2}}{R_{3}}\right)\right) L\right\}
$$

The payoff to the creditor under renegotiation then satisfies

$$
D=(1-\alpha) L+\alpha\left[C+R_{2}+\min \left\{-\left(\frac{C+R_{2}-R_{3}}{s}\right),\left(1-\left(\frac{C+R_{2}}{R_{3}}\right)\right) L\right\}\right]
$$

Because the payoffs to the bank and the creditor are zero-sum, HM show that defaults occur if and only if $D \geq \bar{D}$. It follows that the payoff will be exactly like a debt contract. If the bank holds the loan to maturity, it receives $D$ in period 2 if the borrower can avoid default and $\bar{D}$ in period 2 if he cannot.

For simplicity, I assume that the only period 2 uncertainty in the model is over $R_{2}$. Let $G(C)$ represent the expected payoff to a loan to a good borrower, which satisfies

$$
G(C)=\bar{D} \int_{R_{2}^{*}}^{\infty} h\left(R_{2}\right) d R_{2}+\int_{-\infty}^{R_{2}^{*}} D\left(C, R_{2}\right) h\left(R_{2}\right) d R_{2}
$$

where $R_{2}^{*}$ represents the minimum realization of $R_{2}$ which leaves the borrower solvent. By equation (2.2), $R_{2}^{*}$ satisfies

$$
R_{2}^{*}=\bar{D}-C-L
$$


To evaluate the model, it is useful to consider how realizations of the borrower's cash position, $C$, influence the expected payoff to the acquiring bank. It is easy to show that $G$ is increasing and concave in $C$. Differentiating equation ?? with respect to $C$ yields

$$
\frac{\partial G}{\partial C}=\int_{-\infty}^{R_{2}^{*}} \frac{\partial D}{\partial C} h\left(R_{2}\right) d R_{2}>0
$$

over the values of $C$ for which $\partial D / \partial C$ is defined. This includes all values of $C$ except $C=R_{3}-R_{2}$. At this value of $C$ the payoff when the bank makes the take-it-or-leave-it offer is kinked. When $C>R_{3}-R_{2}$,

$$
\frac{\partial D}{\partial C}=\alpha\left(1-\frac{1}{s}\right)>0,
$$

and when $C<R_{3}-R_{2}$

$$
\frac{\partial D}{\partial C}=\alpha\left(1-\frac{L R_{2}}{R_{3}}\right)>0 .
$$

The second derivative satisfies

$$
\frac{\partial^{2} G}{\partial C^{2}}=-2 \frac{\partial D}{\partial C} h\left(R_{2}^{*}\right)<0
$$

\subsection{Conditions for Nash equilibria}

\subsubsection{N ash Conditions without guarantees}

First, consider the case where the regulatory authority has credibility. Suppose that it deviated and designated all of the assets as suitable. Let $\Pi_{c}^{\prime}$ represent the payoff to the regulatory authority under credibility with no loss-coverage guarantee when it deviates under credibility. In this case, the regulator sells all of the assets, but suffers the penalty $P$.

$$
\Pi_{c}^{\prime}=G-b-P .
$$


By equation 3.1, it follows that the credibility case with no guarantee will be a Nash equilibrium if and only if $\Pi_{c} \geq \Pi_{c}^{\prime}$, i.e. if

$$
P \geq \pi[G-b-L]
$$

Second, consider the case where the regulatory authority lacks credibility. Suppose that it deviated and properly designated the bad assets as such and liquidated them. Let $\Pi_{n}^{\prime}$ represent the payoff to the regulatory authority under lack of credibility with no put-option guarantee when it correctly classifies all of the unsuitable assets, liquidating the unsuitable assets. $\Pi_{n}^{\prime}$ satisfies

$$
\Pi_{n}^{\prime}=\pi L+(1-\pi)[\pi L+(1-\pi) G-b]
$$

It follows that the lack of credibility case with no put option guarantee will be a Nash equilibrium if and only if $\Pi_{n c} \geq \Pi_{n c}^{\prime}$, i.e. if

$$
P \leq \pi[(1-\pi)(G-L)-b]
$$

\subsubsection{Nash conditions with put guarantee}

Let $\Pi_{c}^{p \prime}$ represent the payoff to the regulatory authority under complete credibility when a put guarantee of magnitude $\Lambda$ is offered and the regulatory authority improperly designates all of the assets as suitable. In this case, the regulatory authority would sell all of the assets, but suffer the penalty $P$ plus the net cost of the put-option guarantee, $\Lambda-L$ on all returned assets. $\Pi_{c}^{p \prime}$ satisfies

$$
\Pi_{c}^{p \prime}=V_{u}^{p}-(\Lambda-L)\left[\pi+(1-\pi) F\left(C^{*}\right)\right]-P .
$$

By equation 4.4, the credibility case with a put option guarantee of $\Lambda$ will be a Nash equilibrium if and only if $\Pi_{c}^{p} \geq \Pi_{c}^{p \prime}$, i.e. if

$$
P \geq \pi\left(V^{p}-\Lambda\right)
$$


Let $\Pi_{n}^{p \prime}$ represent the payoff to the regulatory authority under lack of credibility when a put guarantee of magnitude $\Lambda$ is offered and it correctly classifies all of the unsuitable assets as unsuitable. $\Pi_{n}^{p \prime}$ satisfies

$$
\Pi_{n}^{p \prime}=\pi L+(1-\pi)\left[\pi(\Lambda-b)+(1-\pi) V^{p}-(\Lambda-L) F\left(C^{*}\right)\right]
$$

It follows that the lack of credibility case with an unenforceable put option guarantee will be a Nash equilibrium if and only if $\Pi_{n}^{p} \geq \Pi_{n}^{p \prime}$. By equation 4.8, the lack of credibility case is a Nash equilibrium if and only if

$$
P \leq \pi\left[(1-\pi)\left(V^{p}-\Lambda\right)-\pi b\right]
$$

\subsubsection{Nash conditions with Loss-sharing arrangement}

Let $\Pi_{c}^{l \prime}$ represent the payoff to the regulatory authority under complete credibility when a loss-sharing arrangement is offered but the regulatory authority misclassifies all of the assets as suitable. In this case, the regulator sells all of the assets, but suffers the penalty $P$ and the cost of the loss-sharing arrangement. $\Pi_{c}^{l \prime}$ satisfies

$$
\Pi_{c}^{l \prime}=G-b^{\prime}-P-\pi \phi(\bar{D}-L)
$$

The credibility case under the loss-sharing arrangement will be a Nash equilibrium if and only if $\Pi_{c}^{l} \geq \Pi_{c}^{l l}$. By equation 5.4, this requires

$$
P \geq \pi\left(G-b^{\prime}\right)-\pi[\phi \bar{D}+(1-\phi) L]
$$

Alternatively, Let $\Pi_{n}^{l \prime}$ represent the payoff to the regulatory authority under no credibility when a loss-sharing arrangement is offered but the regulatory authority correctly classifies all of the unsuitable assets as unsuitable. In this case, the regulator only sells the suitable assets, but the acquiring bank believes that the share of unsuitable assets is equal to that in the population. $\Pi_{n}^{l l}$ therefore satisfies

$$
\Pi_{n}^{l \prime}=\pi L+(1-\pi)\left[\begin{array}{c}
\pi V_{u}^{l}+(1-\pi) V_{s}^{l} \\
-\phi \int_{0}^{\infty} \int_{-\infty}^{\bar{R}_{2}(C)}\left[\bar{D}-D\left(C, R_{2}\right)\right] h\left(R_{2}\right) d R_{2} f(C) d C
\end{array}\right]
$$


Note that the latter term incorporates the expected payoff for good loans over all of the purchased assets because the regulatory authority understands that only good loans are to be sold. By equation 5.3, $\Pi_{n}^{l \prime}$ satisfies

$\Pi_{n}^{\prime \prime}=\pi L+(1-\pi)\left[\begin{array}{c}\pi\left(V_{u}^{l}-\phi \int_{0}^{\infty} \int_{-\infty}^{\bar{R}_{2}(C)}\left[\bar{D}-D\left(C, R_{2}\right)\right] h\left(R_{2}\right) d R_{2} f(C) d C\right) \\ +(1-\pi)\left(G-b^{\prime}\right)\end{array}\right]$

By equation 5.1, $\Pi_{n}^{l /}$ satisfies

$$
\begin{aligned}
\Pi_{n}^{\prime \prime} & =\pi L+(1-\pi)\left[\pi L+(1-\pi) G-b^{\prime}\right] \\
& +\phi \pi(1-\pi)\left[(\bar{D}-L)-\int_{0}^{\infty} \int_{-\infty}^{\bar{R}_{2}(C)}\left[\bar{D}-D\left(C, R_{2}\right)\right] h\left(R_{2}\right) d R_{2} f(C) d C\right]
\end{aligned}
$$

The latter term reflects the difference between the expected payoff of the losssharing arrangement to the acquiring bank, and the true expected payoff of the loss-sharing arrangement. It is positive because the regulatory authority deviates by only selling good assets.

By equation 5.6, the lack of credibility case under the loss-sharing arrangement will be a Nash equilibrium if and only if

$$
\begin{aligned}
P & \leq \pi(1-\pi)(G-L)-\pi b^{\prime} \\
& -\phi \pi(1-\pi)\left[(\bar{D}-L)-\int_{0}^{\infty} \int_{-\infty}^{\bar{R}_{2}(C)}\left[\bar{D}-D\left(C, R_{2}\right)\right] f\left(R_{2}\right) d R_{2} h(C) d C\right]
\end{aligned}
$$




\section{R eferences}

[1] Balbirer, Sheldon, D., Jud, G. Donald, and Frederick W. Lindahl (1992), "Regulation, Competition, and Abnormal Returns in the Market for Failed Thrifts," J ournal of Financial Economics, 31, 107-131.

[2] Benveniste, Larry, Dennis R. Capozza, Roger Kormendi, and William Wilhelm, "Contract Design for Problem Asset Disposition," J ournal of the American Real Estate and Urban Economics Association, 22(1), 149-167.

[3] Carns, Frederick S. and Lynn A. Nejezchleb (1992), "Bank Failure Resolution: The Cost Test and the Entry and Exit of Resources in the Banking Industry," The FDIC Banking Review, 5, 1-14.

[4] Ely, David P., and Nikhil P. Varaiya (1997), "Assessing the Resolution of Insolvent Thrift Institutions Post FIRREA: The Impact of Resolution Delays," J ournal of Financial Services Research, 11(3), 255-282.

[5] Federal Deposit Insurance Corporation (1998), Managing the crisis: The FDIC and RTC experience, 1980-1994.

[6] Gardner, Roy, and Roger D. Stover (1997), "The Role of Information in Resolution and Trust Corporation Auctions of Failed Bank Thrifts," J ournal of Financial Services Research, 14(3), 209-221.

[7] Gupta, Atul, LeCompte, Richard L. B., and Lalatendu Misra (1993), "FSLIC Assistance and the Wealth Effects of Savings and Loan Acquisitions," J ournal of M onetary E conomics, 31, 117-128. 
[8] Gupta, Atul, LeCompte, Richard L. B., and Lalatendu Misra (1997), "Taxpayer Subsidies in Failed Thrift Resolution: The Impact of FIRREA," J ournal of M onetary Economics, 39, 327-339.

[9] Hart, O. and J. Moore (1998), "Default and Renegotiation: A Dynamic Model of Debt," Quarterly J ournal of E conomics, 113, 1-42.

[10] James, Christopher, and Peggy Wier (1987), "An Analysis of FDIC Failed Bank Auctions," J ournal of Monetary Economics, 20, 141-153.

[11] James, Christopher (1991), "The Losses Realized in Bank Failures," J ournal of Finance, 44(4), 1991.

[12] Rosengren, Eric S., and Katerina Simons (1992), "The Advantages of Transferable Puts for Loans at Failed Banks," New England Economic Review, March/April, 3-11.

[13] Rosengren, Eric S., and Katerina Simons (1994), "Failed Bank Resolution and the Collateral Crunch: The Advantages of Adopting Transferable Puts," J ournal of the A merican Real Estate and U rban E conomics Association, 22(1), 135-147.

[14] Stover, Roger D. (1997), "Early Resolution of Troubled Financial Institutions: An Examination of the Accelerated Resolution Program," J ournal of Banking and Finance, 21, 1179-1184. 